\title{
Применение метода атомно-слоевого осаждения для получения наноструктурированных покрытий $\mathrm{ITO} / \mathrm{Al}_{2} \mathrm{O}_{3}$
}

\author{
(С) Л.К. Марков ${ }^{1}$, А.С. Павлюченко ${ }^{1}$, И.П. Смирнова ${ }^{1}$, М.В. Меш ${ }^{2}$, Д.С. Колоколов ${ }^{2,3}$ \\ ${ }^{1}$ Физико-технический институт им. А.Ф. Иоффе Российской академии наук, \\ 194021 Санкт-Петербург, Россия \\ ${ }^{2}$ АО „СКТБ Кольцова“, \\ 198097 Санкт-Петербург, Россия \\ ${ }^{3}$ Институт химии, Санкт-петербургский государственный университет, \\ 198504 Санкт-Петербург, Россия \\ E-mail: I.markov@mail.ioffe.ru
}

Поступила в Редакцию 11 декабря 2020 г.

В окончательной редакции 19 декабря 2020 г.

Принята к публикации 19 декабря 2020 г.

На полученные методом электронно-лучевого испарения наноструктурированные оптически прозрачные и проводящие покрытия из оксида индия + олова методом атомно-слоевого осаждения наносились дополнительные слои $\mathrm{Al}_{2} \mathrm{O}_{3}$ нанометровой толщины. Использовались покрытия из оксида индия + олова, содержащие нитевидные кристаллы преимущественно вертикальной ориентации и обладающие эффективным показателем преломления, монотонно убывающим в направлении, перпендикулярном плоскости подложки. Изучалось влияние толщины наносимого слоя $\mathrm{Al}_{2} \mathrm{O}_{3}$ на оптические характеристики получаемых образцов. Показано, что применение метода атомно-слоевого осаждения позволяет равномерно покрывать защитными оболочками нитевидные кристаллы наноструктурированных пленок из оксида индия +олова большой толщины, в которых верхние нити затеняют нижележащие, что позволит получать более стойкие к воздействию внешней среды просветляющие проводящие покрытия с требуемыми параметрами. При нанесении защитного слоя $\mathrm{Al}_{2} \mathrm{O}_{3}$ сохраняется градиентный характер показателя преломления, присущий исходной пленке ITO.

Ключевые слова: метод атомно-слоевого осаждения, наноструктурированные пленки ITO.

DOI: 10.21883/FTP.2021.04.50742.9574

\section{1. Введение}

Нанесение оптически прозрачных пленок рассчитанной толщины на границу раздела двух сред с разным значением показателя преломления - один из классических способов просветления оптических изделий, использующий конструктивную интерференцию с целью снижения френелевского отражения на границе раздела сред. Однако однослойная изотропная пленка эффективна только для монохроматического излучения, распространяющегося в одном направлении. Поэтому для достижения просветления в широком диапазоне длин волн приходится применять покрытия, содержащие большое количество слоев (вплоть до 6-8). С другой стороны, альтернативный вариант подавления френелевского отражения предоставляют оптические покрытия, в которых показатель преломления материала меняется монотонно в направлении, перпендикулярном плоскости с нанесенным покрытием. При этом оптимального просветления можно достичь в случае, когда показатель преломления пленки меняется в пределах значений, ограничивающих его среду [1]. Отличительной чертой таких, так называемых градиентных, покрытий становится отсутствие зависимости коэффициента пропускания от длины волны или направления распространения излучения.

Для получения покрытия с ощутимым градиентом показателя преломления могут быть использованы разные подходы, один из которых заключается в создании двухкомпонентной среды с размерами частиц значительно меньше длины волны излучения. В этом случае свет воспринимает среду как оптически однородную, с неким усредненным показателем преломления. Значение этого, эффективного, показателя преломления будет соответственно определяться процентным содержанием каждого вещества в составе покрытия. Действуя таким образом, (теоретически) можно получить весь спектр значений эффективного показателя преломления, лежащий в пределах значений показателей преломления исходных компонент.

Реализация подхода, позволяющего создать среду с усредненным значением показателя преломления, изложена, например, в работе [2], где совместным распылением оксида индия + олова (ITO) и диоксида кремния $\left(\mathrm{SiO}_{2}\right)$ получали слои с разным значением показателя преломления, а в работе [3] также благодаря совместному распылению материалов $\mathrm{SiO}_{2}$ и $\mathrm{TiO}_{2}$ были получены среды, в которых показатель преломления варьировался в диапазоне $1.45-2.47$. В работах $[4,5]$ для получения проводящей среды с модифицированным показателем преломления наносились слои, состоящие из мелкодисперсных частиц оксида сурьмы и олова (antimonydoped tin oxide, ATO) или диоксида кремния, на которые наносился слой ITO.

В качестве аналога двухкомпонентной среды можно также рассматривать слои с различной степенью пористости при том же, упомянутом выше, условии, 
что размеры пор материала значительно меньше длины волны излучения. В этом случае также можно говорить о квазиоднородной среде, характеризующейся определенным значением эффективного показателя преломления. Соответственно, чем больше в среде содержится пор, тем ближе значение показателя преломления стремится к 1. Таким образом, среды с переменной пористостью могут быть рассмотрены как имеющие градиент эффективного показателя преломления материала.

Интересно, что, хотя основные технологические подходы к формированию таких покрытий только формируются [6], этот способ органично встроен в жизнь некоторых насекомых в природе [7,8]. В частности, поверхность роговицы глаза некоторых мотыльков содержит наноразмерные сосочки переменной толщины, формирующие градиентные покрытия, что приводит к отсутствию отражения на внешней границе глаза и соответственно к лучшей ориентации, особенно в условиях слабой освещенности.

Одним из способов получения пористых сред является осаждение материала при наклонном падении [9]. Сущность метода заключается в том, что при наклонном падении неоднородности, возникающие на первых стадиях напыления, затеняют участки на подложке, и дальнейшее осаждение материала идет неравномерно по площади подложки. Таким образом образуется пористая среда, причем степень пористости зависит от угла падения материала. Создание пористых сред для материала ITO данным методом было показано в работах $[10,11]$, а в работе [12] последовательным нанесением нескольких слоев материала оксида индия и олова при различных углах напыления создавалось градиентное покрытие, использовавшееся для более эффективного вывода света из светодиодного кристалла.

Другой способ создания пористой среды с градиентом показателя преломления представлен в [13], где использовалась декомпозиция боросиликатных стекол при напылении при высоких температурах с последующим травлением.

Интересную возможность создания градиентных покрытий предоставляет способность материала ITO при определенных условиях нанесения формировать кристаллы вытянутой формы (nanowires, nanowhisker, nanorods) [14-19], рост которых осуществляется по механизму пар-жидкость-кристалл (ПЖК) (vapor-liquidsolid, VLS в англоязычном варианте) [20,21]. Поскольку в этом случае рост кристаллов идет по границе раздела кристалл-жидкость из капель расплава нанометрового размера, поперечные размеры возникающих нитевидных кристаллов также крайне малы и составляют, как правило, 10-20 нм, что существенно меньше длины волны оптического излучения. Поскольку процесс роста идет одновременно из множества источников на подложке, образуются самоорганизующиеся наноразмерные структуры в виде ,леса“ из „нанонитей“. Конкуренция между соседними нитями приводит к тому, что часть из них прекращает рост, а часть продолжает рост вплоть до верхней границы пленки. Этот факт наряду с тем, что часть нитей ориентирована не строго перпендикулярно подложке, приводит к явно выраженному градиенту плотности материала при удалении от подложки и в результате к градиенту эффективного показателя преломления. В работе [22] компьютерным моделированием среды по экспериментальным спектральным зависимостям коэффициентов пропускания и отражения света были восстановлены профили распределения вещества и значения эффективного показателя преломления в наноструктурированных самоорганизующихся пленках ITO, полученных методом электронно-лучевого испарения и осаждения на подложки, нагретые до температур выше $400^{\circ} \mathrm{C}$. Расчет показал, что в таких пленках эффективный показатель преломления имеет монотонный характер и на внешней границе пленки приближается к значениям, близким к 1, с производной, стремящейся к нулю. При этом рост пленки ITO начинается с более плотного (зародышевого) слоя, имеющего показатель преломления, близкий к показателю преломления неструктурированного материала.

Применение оптических проводящих покрытий, содержащих кристаллы вытянутой формы, с целью улучшения характеристик светоизлучающих диодов представлено в работах [23,24].

Поскольку структурированные пленки ITO на внешних границах имеют область с крайне низким значением эффективного показателя преломления, при размещении оптических элементов на поверхности пленки можно существенно повысить контраст показателей преломления оптического элемента и окружающей среды. Таким образом в работе [25] за счет высокого оптического контраста удалось значительно повысить добротность нанолазера на основе перовскитного кристалла при размещении его на поверхности пленок структурированного ITO.

В работе [26] изучалось влияние дополнительного слоя $\mathrm{SiO}_{2}$, наносимого поверх наноструктурированных градиентных пленок ITO методом магнетронного распыления, на их оптические характеристики. Было показано, что при равномерном покрытии нитей ITO дополнительный слой $\mathrm{SiO}_{2}$ может усиливать просветляющие свойства покрытия. В то же время наноразмерные нити ITO обладают настолько развитой поверхностью, что могут быть подвержены воздействию окружающей среды, приводящей к деградации оптических характеристик материала. Поэтому нанесение химически стойкого прозрачного материала, покрывающего всю поверхность нитевидных кристаллов тонким, наноразмерным, слоем, также полезно с точки зрения улучшения эксплуатационных характеристик просветляющих покрытий на основе наноструктурированного ITO. С учетом характера нанесения материала при магнетронном распылении становится затруднительным покрыть равномерным слоем затеняющие друг друга ветви „леса“, состоящего из нитевидных кристаллов, начиная с определенной толщины ITO покрытия. 
В настоящей работе для нанесения химически стойких прозрачных слоев на элементы наноструктурированного ITO был использован метод атомно-слоевого осаждения (ACO). Данный метод заключается в осаждении тонких пленок из газовой фазы. Процесс основан на последовательных химических реакциях между парами реагентов, происходящих на поверхности подложки. Ключевой особенностью АСО является то, что количество вступающего в реакцию реагента строго определяется количеством свободных связей на поверхности подложки, а излишек реагентов удаляется из реактора. Кроме того, образуется химическая связь между атомами осаждаемого вещества и атомами подложки. Все это позволяет контролировать толщину получаемых пленок с высокой точностью. Исходя из сказанного выше, при выборе соответствующих режимов нанесения можно достичь равномерного покрытия создаваемой пленкой поверхности материала подложки независимо от ее геометрии и степени развитости. Для создания прозрачной оболочки нитевидных кристаллов ITO в экспериментах настоящей работы наносились слои $\mathrm{Al}_{2} \mathrm{O}_{3}$. Материал известен своими отличными изоляционными свойствами, химической стойкостью, в том числе низкой проницаемостью щелочных ионов, а также малым поглощением света в широком диапазоне длин волн излучения [27].

\section{2. Результаты эксперимента и их обсуждение}

Наноструктурированные самоорганизующиеся пленки ITO, имеющие в составе вытянутые нитевидные кристаллы, формировались по технологии, описанной в работе [28]. Слой ІТО осаждался со скоростью $\sim 10$ нм/мин методом электронно-лучевого испарения при нагреве подложки до температуры $450^{\circ} \mathrm{C}$ с последующим напуском в вакуумную камеру азота ОСЧ до давления, близкого к атмосферному ( 800 мбар), и дальнейшей выдержкой образца в атмосфере азота в течение 10 мин без выключения нагрева. Как мы обсуждали выше, плотность таких пленок существенно ниже плотности неструктурированных плотноупакованных пленок и соответственно толщина структурированных пленок в разы превышает толщину пленок без пор. Поскольку контроль толщины пленок проводился в процессе их нанесения с помощью кварцевого датчика, измеряющего массу наносимого материала, а калибровка датчика осуществлялась на сплошном плотноупакованном материале, в дальнейшем мы будем для простоты изложения количество материала, наносимое в одном процессе напыления пленки, характеризовать толщиной пленки без пустот, содержащей такое же количество материала. В этом случае будет говориться о количестве материала „В эквиваленте плотной пленки“, т.е. фраза „пленка толщиной $x$ в эквиваленте плотной пленки“ означает, что на подложку было осаждено такое же количество материала, как при нанесении плотноупакованной пленки толщиной $x$.

Процесс атомно-слоевого осаждения слоев $\mathrm{Al}_{2} \mathrm{O}_{3}$ проводился на установке Picosun P-300B. Осаждение проводилось путем чередующихся напусков реагентов $\mathrm{TMA}+\mathrm{H}_{2} \mathrm{O}$ (ТМА - триметилалюминий). Время напуска составляло $0.1 \mathrm{c}$, время продувки составляло $3 \mathrm{c}$ для ТМА и 5 с для воды. В качестве газа-носителя использовался азот ОСЧ. Толщину наносимого слоя рассчитывали исходя из количества проведенных циклов процесса.

Изучение оптических характеристик пленок проводилось на тестовых образцах, представляющих собой предметные стекла толщиной 1.2 мм, на одну сторону которых наносили исследуемые пленки. Спектры пропускания и отражения образцов исследовались на спектрорадиометре Optronic Laboratories OL 770. Излучение падало на образец со стороны пленки, нормально к его поверхности.

$\mathrm{B}$ первых экспериментах слой $\mathrm{Al}_{2} \mathrm{O}_{3}$ толщиной 1,10 и 20 нм наносили на пленку ITO толщиной 50 нм в эквиваленте плотной пленки (реальная толщина пленки с учетом пустот составила 160 нм). Температура процесса нанесения материала в методе АCO составляла $300^{\circ} \mathrm{C}$. Изображения покрытий, полученные с помощью растрового электронного микроскопа (РЭМ), представлены на рис. 1. Как показали эксперименты, применение метода ACO дало положительный результат: слой изолятора равномерно покрывает нитевидные кристаллы по всей их длине. При этом кривые измеренных зависимостей пропускания от длины волны излучения для образцов со слоем $\mathrm{Al}_{2} \mathrm{O}_{3}$ толщиной 1 и 10 нм практически совпадают с кривой пропускания исходной пленки ITO, а нанесение пленки толщиной 20 нм приводит к небольшому $(1-1.5 \%)$ падению коэффициента пропускания пленки практически во всем измеренном диапазоне длин волн излучения (400-1100 нм), что объясняется комбинацией двух факторов. Во-первых, как видно из рис. 1, суммарная плотность материала в образце с $20 \mathrm{HM} \mathrm{Al}_{2} \mathrm{O}_{3}$ существенно выше. Это приводит к изменению градиента показателя преломления в пленке и соответственно влияет на коэффициент пропускания света. Действительно, как показали измерения, отражение света от образца c пленкой $\mathrm{Al}_{2} \mathrm{O}_{3}$ толщиной $20 \mathrm{Hм}$ слегка превышает отражение от образцов с исходной пленкой ITO, а также от пленок с защитными слоями толщиной 1 и 10 нм. Вторым фактором, приводящим к незначительному падению коэффициента пропускания пленки с защитным покрытием толщиной 20 нм, является появление дополнительного поглощения света образцом. Экспериментально измеренные спектры пропускания и отражения образцов дают возможность определения поглощения света в образце по формуле

$$
A=1-(T+R),
$$

где $A, T$ и $R$ - коэффициенты поглощения, пропускания и отражения соответственно. Как показали измерения, 

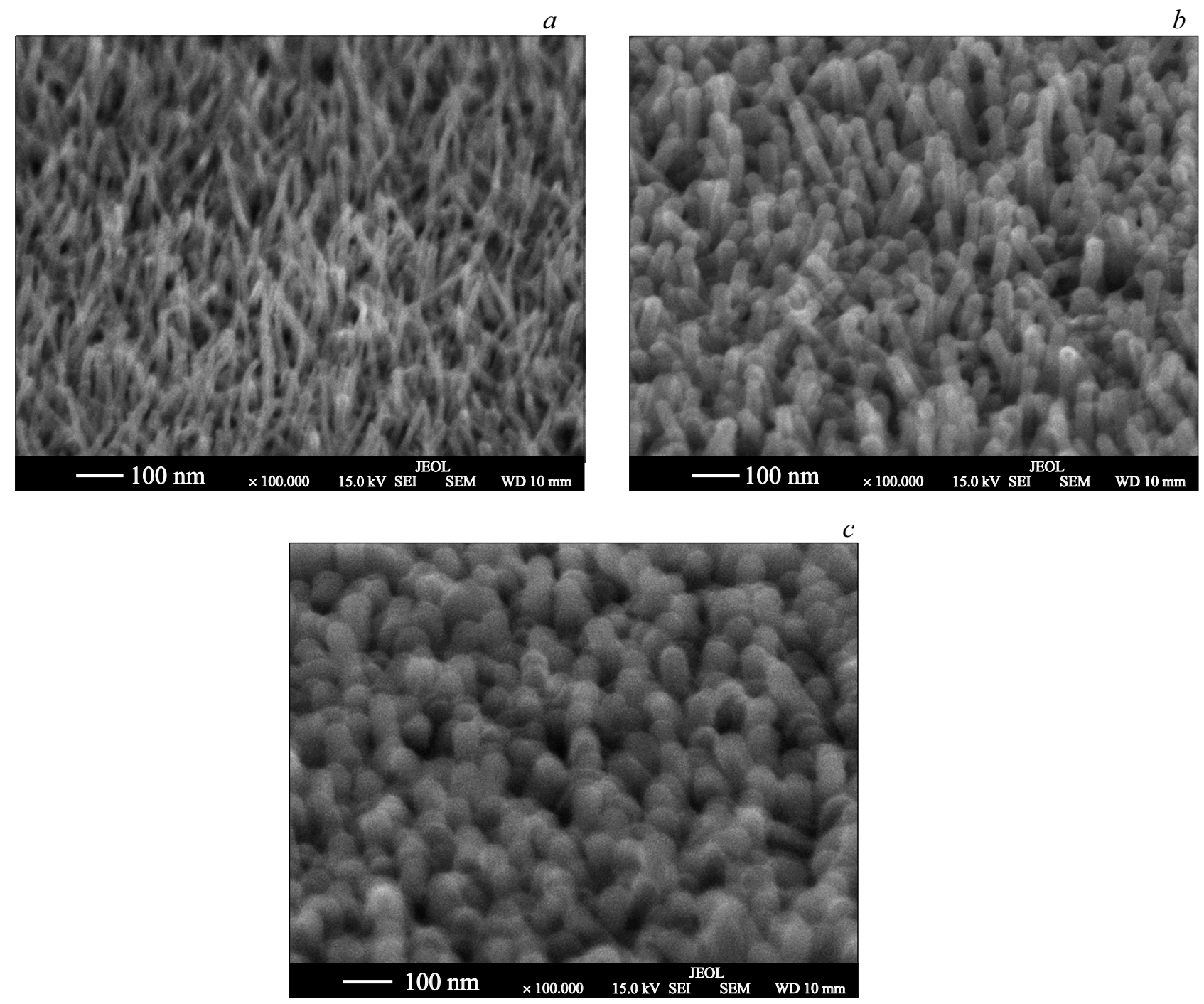

Рис. 1. РЭМ-изображения пленок ITO толщиной 50 нм в эквиваленте плотной пленки, на которую нанесены слои $\mathrm{Al}_{2} \mathrm{O}_{3}$ толщиной $1(a), 10(b), 20$ нм $(c)$. Угол наклона подложки к углу зрения составляет $15^{\circ}$ для всех изображений. Изображение исходной пленки ITO не приводится.

образец с покрытием $\mathrm{Al}_{2} \mathrm{O}_{3}$ толщиной 20 нм вместе с дополнительным отражением обнаружил появление незначительного поглощения. Возможную причину появления поглощения света в этом образце и способ ее устранения мы рассмотрим далее при обсуждении покрытий на основе более толстых пленок ITO.

Как обсуждалось в статье [26], нанесение методом магнетронного распыления пленки $\mathrm{SiO}_{2}$ толщиной 30 нм на такие же исходные пленки ITO приводило к заметному просветлению пленки, что может быть связано с модификацией профиля эффективного показателя преломления пленки вследствие более низкого значения показателя преломления $\mathrm{SiO}_{2}$ по сравнению с показателем преломления ITO. Показатель преломления материала $\mathrm{Al}_{2} \mathrm{O}_{3}$, полученного методом $\mathrm{ACO}$, зависит от подложки, на которую он нанесен. Так, например, согласно данным работы [27], показатель преломления пленки, нанесен- ной на подложку $\mathrm{SiO}_{2} / \mathrm{Si}(100)$, составляет $1.64-1.65$ в диапазоне длин волн 400-800 нм соответственно. Конечно, определить точно показатель преломления нанометрового слоя материала, нанесенного на нанонити ITO, не представляется возможным, но можно предположить, что величина и дисперсия показателя преломления такой пленки будут схожими с полученными в [27]. Учитывая, что показатель преломления материала ITO принимает значения от 2.06 до 1.77 в диапазоне длин волн излучения 400-800 нм (см., например, [29]), достичь заметного просветления, нанося на нити близкий по значению показателя преломления слой $\mathrm{Al}_{2} \mathrm{O}_{3}$, проблематично.

Исходя из сказанного выше можно считать, что в условиях проведенных экспериментов слой $\mathrm{Al}_{2} \mathrm{O}_{3}$ толщиной 10 нм является оптимальным для пленок ITO указанной толщины, поскольку обеспечивает защиту покрытия, не ухудшая его оптических характеристик. 

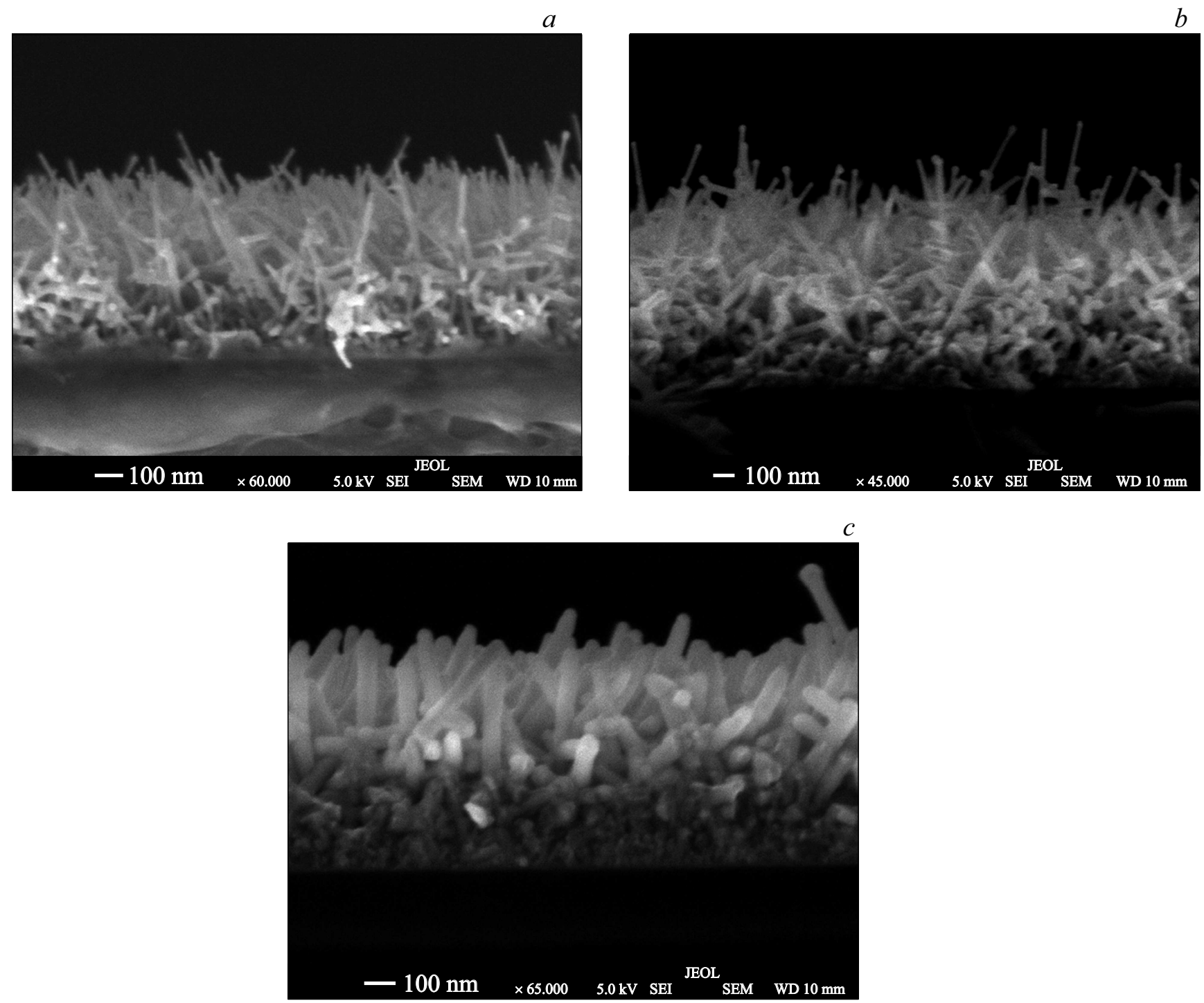

Рис. 2. РЭМ-изображения поперечных сколов пленок ITO толщиной 200 нм в эквиваленте плотной пленки $(a)$, на которую нанесены слои $\mathrm{Al}_{2} \mathrm{O}_{3}$ толщиной 10 нм при температуре осаждения $300^{\circ} \mathrm{C}(b)$ и 20 нм при температуре осаждения $175^{\circ} \mathrm{C}(c)$.

Наибольший интерес, как обсуждалось выше, представляет возможность нанесения методом АCO защитных покрытий на более толстые пленки наноструктурированного ITO, поскольку в них верхние нити затеняют нижележащие. С этой целью в эксперименте использовались пленки ITO толщиной 200 нм в эквиваленте плотной пленки (реальная толщина пленки с учетом пустот составила $\sim 700$ нм). Толщина таких пленок, сопоставимая с длиной волны видимого излучения, обеспечивает им достаточные для большинства применений прозрачность и проводимость, однако требует учета интерференционных эффектов, снижающих коэффициент пропускания пленки. Изображение пленки, полученное в растровом электронном микроскопе, приведено на рис. 2,a. Осаждение слоя $\mathrm{Al}_{2} \mathrm{O}_{3}$ толщиной $10 \mathrm{Hм}$ (рис. 2,b) при температуре $300^{\circ} \mathrm{C}$ не привело к заращиванию нитевидных кристаллов ITO по всей длине кристалла, в отличие от того, как это происходило на пленках ITO меньшей толщины.

Увеличение толщины слоя $\mathrm{Al}_{2} \mathrm{O}_{3}$ до 20 нм обеспечило полное закрытие всех нитей защитным слоем, однако пропускание света пленкой во всем исследованном диапазоне длин волн излучения существенно уменьшилось. Спектральные зависимости пропускания и отражения полученных образцов приведены на рис. 3. Там же для сравнения приводятся спектральные зависимости, измеренные на образце с исходной пленкой ITO (кривые 1). На рис. 4 приведены спектральные зависимости коэффициента поглощения этих образцов, рассчитанные по формуле (1). Как видим, эффект увеличения поглощения при нанесении защитного покрытия, мало заметный на пленках ITO малой толщины, проявился при увеличении толщины пленки в несколько раз. Для получения покрытия с оптимальным коэффициентом 

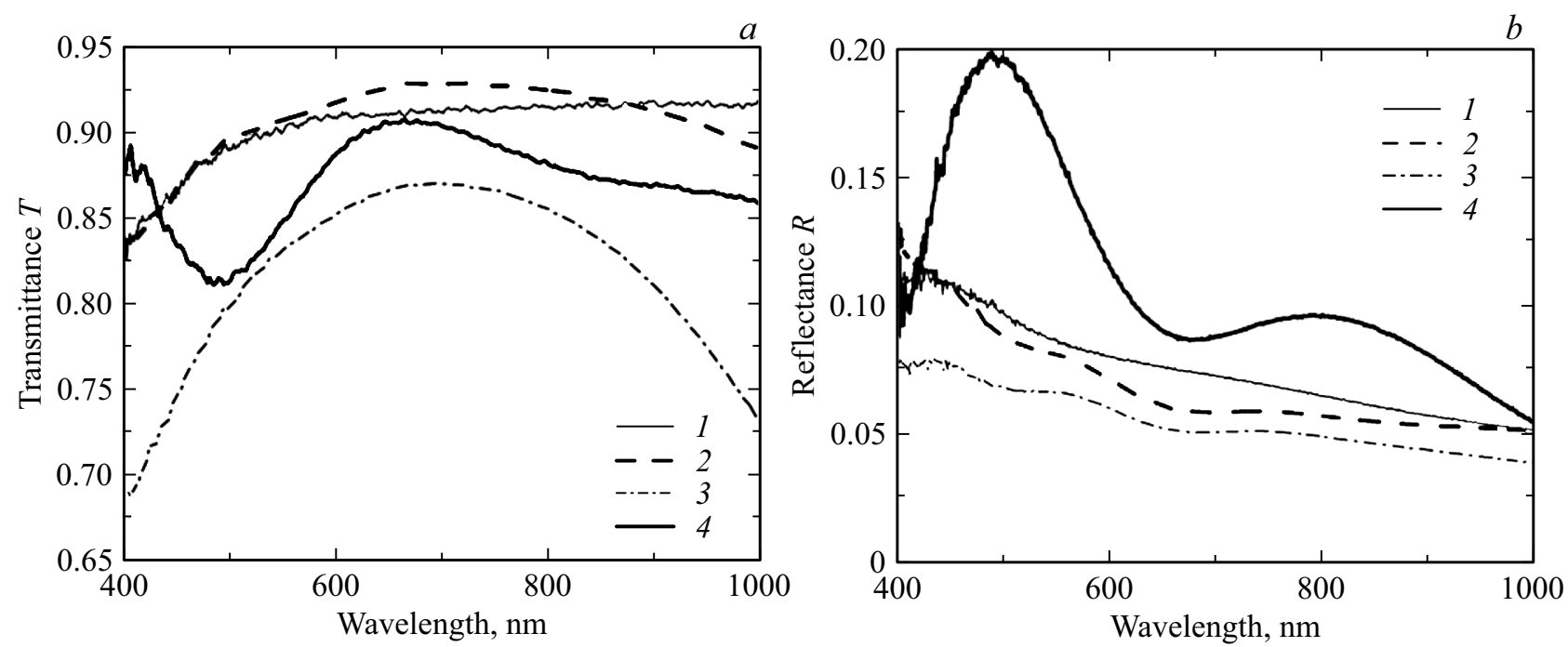

Рис. 3. Спектры отражения $(a)$ и пропускания $(b)$ образцов: 1 - наноструктурированный ITO (200 нм в эквиваленте плотной пленки); 2 - наноструктурированный ITO (200 нм в эквиваленте плотной пленки) $/ \mathrm{Al}_{2} \mathrm{O}_{3}(20$ нм), полученный при температуре осаждения слоя $\mathrm{Al}_{2} \mathrm{O}_{3} 175^{\circ} \mathrm{C} ; 3$ - наноструктурированный ITO (200 нм в эквиваленте плотной пленки)/ $\mathrm{Al}_{2} \mathrm{O}_{3}(20$ нм), полученный при температуре осаждения слоя $\mathrm{Al}_{2} \mathrm{O}_{3} 300^{\circ} \mathrm{C} ; 4$ - неструктурированный $\mathrm{ITO}(200 \mathrm{Hм}) / \mathrm{Al}_{2} \mathrm{O}_{3}(20$ нм$)$.

пропускания при сохранении полного закрытия нитей ITO слоем $\mathrm{Al}_{2} \mathrm{O}_{3}$ была проведена серия экспериментов по нанесению слоя изолятора при других режимах его осаждения (мы планируем детально обсудить полученные зависимости свойств получаемого покрытия, а также характера осаждения слоя изолятора в рамках другой статьи). Как показали эксперименты, поставленную задачу можно решить уменьшением температуры проведения процесса АCO до значения $175^{\circ} \mathrm{C}$. Изображение поперечного скола пленки ITO, покрытой слоем $\mathrm{Al}_{2} \mathrm{O}_{3}$ толщиной $20 \mathrm{Hм}$, осажденным при $175^{\circ} \mathrm{C}$, приведено на рис. 2,c. Согласно изображению, нити полностью закрыты ровным слоем $\mathrm{Al}_{2} \mathrm{O}_{3}$ планируемой толщины (диаметр нити с покрытием равен $\sim 60 \mathrm{Hм}$ ). Отметим, что уменьшение температуры процесса не привело к заметному изменению структуры пленки, и поэтому покрытие, полученное при $300^{\circ} \mathrm{C}$, на рис. 2 не показано. Спектры поглощения и отражения образцов приведены на рис. 3. Из рисунка видно, что нанесение при температуре $175^{\circ} \mathrm{C}$ дополнительного слоя $\mathrm{Al}_{2} \mathrm{O}_{3}$ незначительно видоизменяет оптические характеристики пленки ITO в видимом диапазоне длин волн. Наблюдается небольшое увеличение коэффициента пропускания образцов в диапазоне длин волн 550-850 нм, возникающее вследствие модификации внешней границы пленки и меньшего отражения света от нее. Как обсуждалось выше, близость значений показателей преломления ITO и $\mathrm{Al}_{2} \mathrm{O}_{3}$ не позволяет добиться существенного просветления, однако в указанном диапазоне длин волн она обеспечивает измеряемый прирост коэффициента пропускания образца. Стоит отметить также, что предпринятое снижение температуры процесса ACO с 300 до $175^{\circ} \mathrm{C}$ позволило практически полностью устранить дополнительное поглощение света, возникающее вслед- ствие нанесения защитного слоя. На рис. 4 приводятся спектральные зависимости коэффициента поглощения света для обоих образцов. Как видно из рисунка, нанесение слоя $\mathrm{Al}_{2} \mathrm{O}_{3}$ при температуре $175^{\circ} \mathrm{C}$ не привело к увеличению поглощения света во всем диапазоне длин волн видимого излучения. В то же время в области ближнего инфракрасного излучения (длины волн $>850$ нм) наблюдается повышение поглощения света в этих образцах.

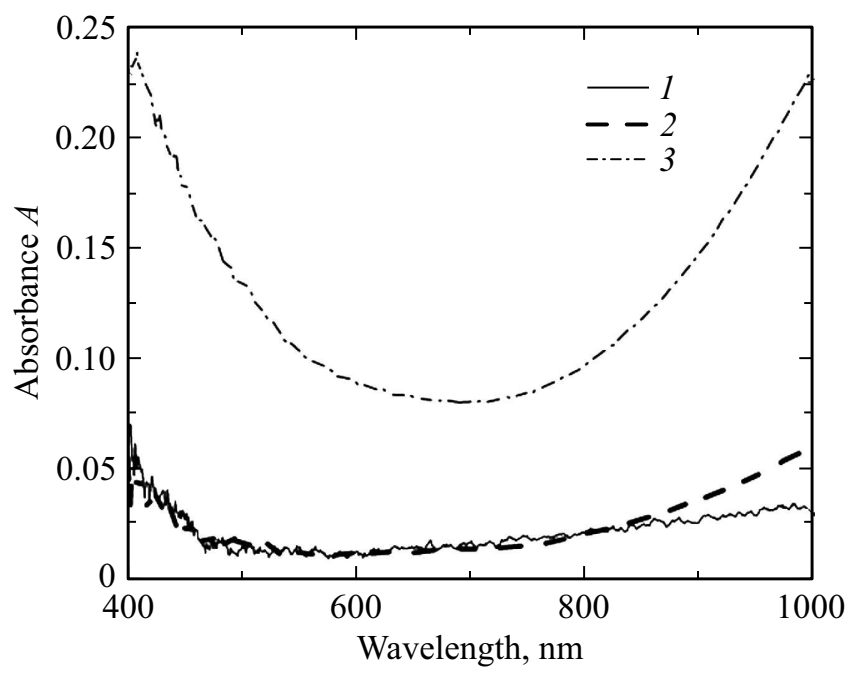

Рис. 4. Спектры поглощения образцов: 1 - наноструктурированный ITO (200 нм в эквиваленте плотной пленки); 2 наноструктурированный ITO (200 нм в эквиваленте плотной пленки) $/ \mathrm{Al}_{2} \mathrm{O}_{3}(20 \mathrm{Hм})$, полученный при температуре осаждения слоя $\mathrm{Al}_{2} \mathrm{O}_{3} 175^{\circ} \mathrm{C} ; 3$ - наноструктурированный ITO (200 нм в эквиваленте плотной пленки) $/ \mathrm{Al}_{2} \mathrm{O}_{3}(20$ нм $)$, полученный при температуре осаждения слоя $\mathrm{Al}_{2} \mathrm{O}_{3} 300^{\circ} \mathrm{C}$. 
Значительное поглощение света в образцах с температурой нанесения слоя $\mathrm{Al}_{2} \mathrm{O}_{3} 300^{\circ} \mathrm{C}$ (рис. 4, кривая 3) может быть объяснено уменьшением содержания кислорода в структуре нитевидных кристаллов, происходящим в процессе роста пленки $\mathrm{Al}_{2} \mathrm{O}_{3}$ вследствие увеличения скорости его диффузии при повышенных температурах. Большая удельная поверхность материала может обеспечить переход большого числа атомов кислорода из структуры пленки ITO в структуру защитной пленки в стадии ее роста. Известно, что именно выбор оптимального уровня содержания кислорода в материале оксида индия + олова обеспечивает компромисс между проводимостью и прозрачностью пленок ITO, и недостаток кислорода приводит к увеличению поглощения света материалом [30].

Сравнение оптических свойств структурированного и неструктурированного покрытий ITO, защищенных пленкой изолятора, проводилось на следующем модельном эксперименте: методом магнетронного распыления в кислородосодержащей плазме при комнатной температуре изготавливался образец с плотной неструктурированной пленкой ITO толщиной 200 нм. В дальнейшем методом ACO поверх нее наносилась пленка $\mathrm{Al}_{2} \mathrm{O}_{3}$ толщиной 20 нм. Таким образом, массовое содержание материала и последовательность нанесения слоев этого образца были такими же, как у образца со структурированной пленкой ITO. Температура нанесения защитной пленки $\mathrm{Al}_{2} \mathrm{O}_{3}$ при нанесении на структурированную и неструктурированную пленки ITO была также одинаковой и составила $175^{\circ} \mathrm{C}$. Соответственно все различия оптических характеристик образцов объясняются только структурированием материала покрытия. На рис. 3 приведены спектры пропускания и отражения такого неструктурированного образца с защитной пленкой. Как и ожидалось, практически во всем измеренном диапазоне длин волн коэффициент пропускания неструктурированного образца заметно ниже, чем структурированного, и приближается к последнему лишь в нескольких точках, соответствующих выполнению условий конструктивной интерференции. Соответственно наблюдается существенно более высокое отражение света от образца с неструктурированной поверхностью. Таким образом, нанесение защитного слоя $\mathrm{Al}_{2} \mathrm{O}_{3}$ на образцы со структурированными пленками ITO, сохраняя градиентный характер пленки, обеспечивает значительное просветление образцов в широком диапазоне длин волн и соответственно направлений, в котором распространяется излучение.

Стоить отметить: несмотря на то что метод $\mathrm{ACO}$, как было показано, позволяет покрывать защитным слоем нитевидные кристаллы большой длины, сопротивление покрытия определяется толщиной зародышевого, плотного слоя ITO, образующегося в начальное время нанесения наноструктурированной пленки. Дальнейшее увеличение толщины пленки идет за счет роста нитевидных кристаллов, не вносящих вклада в проводимость пленки. Поэтому, если толщина зародышевого слоя не обеспечивает необходимую для сильноточных приборов проводимость, может быть использован прием, описанный в $[23,31,32]$, когда на подложке создавался подслой плотного материала ITO с достаточной проводимостью, поверх которого наносилось просветляющее покрытие по описанной в настоящей статье технологии.

\section{3. Заключение}

В рамках настоящего исследования на наноструктурированные пленки ITO, характеризуемые монотонным изменением эффективного показателя преломления в направлении, перпендикулярном плоскости подложки, методом атомно-слоевого осаждения наносился дополнительный слой прозрачного химически стойкого материала $\mathrm{Al}_{2} \mathrm{O}_{3}$. Показано, что применение метода $\mathrm{ACO}$ позволяет равномерно покрывать нанометровым слоем защитного материала нитевидные кристаллы, из которых состоит структурированная пленка ITO. При этом, поскольку метод основан на последовательных химических реакциях между парами реагентов и подложкой, защитное покрытие может быть нанесено на структурированные пленки большой толщины. Оптимизация режимов нанесения материала методом АСО позволила свести к минимуму поглощение света покрытием, возникающее, по всей видимости, вследствие диффузии кислорода из нитей ITO в защитную оболочку в процессе ее роста. Как показали эксперименты, покрытия с защитным слоем $\mathrm{Al}_{2} \mathrm{O}_{3}$ сохраняют градиентный характер показателя преломления, присущий исходной пленке ITO, и даже позволяют добиться дополнительного просветления образцов, однако прирост коэффициента пропускания покрытия минимален вследствие близости показателей преломления материалов ITO и $\mathrm{Al}_{2} \mathrm{O}_{3}$. Результаты работы интересны с точки зрения получения более стойких к воздействию внешней среды просветляющих проводящих покрытий, поскольку большая удельная поверхность наноструктурированных пленок ITO может вызывать ускоренные деградационные процессы, приводящие к потере прозрачности пленок. С этой точки зрения применение материала $\mathrm{Al}_{2} \mathrm{O}_{3}$, известного своими отличными изоляционными характеристиками и химической стойкостью, является вполне обоснованным.

\section{Конфликт интересов}

Авторы статьи заявляют об отсутствии конфликта интересов.

\section{Список литературы}

[1] J.W.S. Rayleigh. Proc. London Math. Soc., 11, 51 (1880).

[2] J.-Y. Cho, K.-J. Byeon, H. Lee. Optics Lett., 36, 3203 (2011).

[3] J.K. Kim, A.N. Noemaun, F.W. Mont, D. Meyaard, E.F. Schubert, D.J. Poxson, H. Kim, C. Sone, Y. Park. Appl. Phys. Lett., 93, 221111 (2008).

[4] P.G. O’Brien, D.P. Puzzo, A. Chutinan, L.D. Bonifacio, G.A. Ozin, N.P. Kherani. Adv. Mater., 22, 611 (2010). 
[5] P.G. O’Brien, Y. Yang, A. Chutinan, P. Mahtani, K. Leong, D.P. Puzzo, L.D. Bonifacio, C.W. Lin, G.A. Ozin, N.P. Kherani. Sol. Energy Mater. Sol. Cells, 102, 173 (2012).

[6] Z.W. Han, Z. Wang, X.M. Feng, B. Li, Z.Z. Mu, J.Q. Zhang, S.C. Niu, L.Q. Ren. Biosurface \& Biotribology, 2, 137 (2016).

[7] M. Kryuchkov, J. Lehmann, J. Schaab, V. Cherepanov, A. Blagodatski, M. Fiebig, V.L. Katanaev. J. Nanobiotechnology, 15, 61 (2017).

[8] M. Kryuchkov, O. Bilousov, J. Lehmann, M. Fiebig, V.L. Katanaev. Nature, 585, 383 (2020).

[9] K. Robbie, L.J. Friedrich, S.K. Dew, T. Smy, M.J. Brett. J. Vac. Sci. Technol. A: Vacuum, Surf., Film., 13, 1032 (1995).

[10] M.F. Schubert, J.-Q. Xi, J.K. Kim, E.F. Schubert. Appl. Phys. Lett., 90, 141115 (2007).

[11] J.K. Kim, T. Gessmann, E.F. Schubert, J.-Q. Xi, H. Luo, J. Cho, C. Sone, Y. Park. Appl. Phys. Lett., 88, 013501 (2006).

[12] J.K. Kim, S. Chhajed, M.F. Schubert, E.F. Schubert, A.J. Fischer, M.H. Crawford, J. Cho, H. Kim, C. Sone. Adv. Mater., 20, 801 (2008).

[13] T. Aytug, A.R. Lupini, G.E. Jellison, P.C. Joshi, I.H. Ivanov, T. Liu, P. Wang, R. Menon, R.M. Trejo, E. Lara-Curzio, S.R. Hunter, J.T. Simpson, M.P. Paranthaman, D.K. Christen. J. Mater. Chem. C, 3, 5440 (2015).

[14] X.Y. Xue, Y.J. Chen, Y.G. Liu, S.L. Shi, Y.G. Wang, T.H. Wang. Appl. Phys. Lett., 88, 201907 (2006).

[15] A.J. Chiquito, A.J.C. Lanfredi, E.R. Leite. J. Phys. D. Appl. Phys., 41, 4 (2008).

[16] H.K. Yu, W.J. Dong, G.H. Jung, J.L. Lee. ACS Nano, 5, 8026 (2011).

[17] R. Rakesh Kumar, V. Gaddam, K. Narasimha Rao, K. Rajanna. Mater. Res. Express, 1, 35008 (2014).

[18] G.O. Setti, D.P. De Jesus, E. Joanni. Mater. Res. Express, 3, 105021 (2016).

[19] A.L. Beaudry, R.T. Tucker, J.M. Laforge, M.T. Taschuk, M.J. Brett. Nanotechnology, 23, 105608 (2012).

[20] G. Meng, T. Yanagida, K. Nagashima, H. Yoshida, M. Kanai, A. Klamchuen, F. Zhuge, Y. He, S. Rahong, X. Fang, S. Takeda, T. Kawai. J. Am. Chem. Soc., 135, 7033 (2013).

[21] H.K. Yu, J.L. Lee. Sci. Rep., 4, 1 (2014).

[22] Л.К. Марков, А.С. Павлюченко, И.П. Смирнова, С.И. Павлов. ФТП, 52, 1228 (2018).

[23] M.J. Park, C.U. Kim, S.B. Kang, S.H. Won, J.S. Kwak, C.-M. Kim, K.J. Choi. Adv. Opt. Mater., 5, 1600684 (2017).

[24] Z. Gong, Q. Li, Y. Li, H. Xiong, H. Liu, S. Wang, Y. Zhang, M. Guo, F. Yun. Appl. Phys. Express, 9, 082102 (2016).

[25] D.I. Markina, A.P. Pushkarev, I.I. Shishkin, F.E. Komissarenko, A.S. Berestennikov, A.S. Pavluchenko, I.P. Smirnova, L.K. Markov, M. Vengris, A.A. Zakhidov, S.V. Makarov. Nanophotonics, 9, 3977 (2020).

[26] Л.К. Марков, А.С. Павлюченко, И.П. Смирнова. ФТП, 53, 1052 (2019).

[27] Y. Kim, S. M. Lee, C.S. Park, S.I. Lee, M.Y. Lee. Appl. Phys. Lett., 71, 3604 (1997).

[28] Л.К. Марков, И.П. Смирнова, А.С. Павлюченко, М.В. Кукушкин, Д.А. Закгейм, С.И. Павлов. ФТП, 50, 1001 (2016).

[29] R.J. Moerland, J.P. Hoogenboom. Optica, 3, 112 (2016).

[30] L. Kerkache, A. Layadi, A. Mosser. J. Alloys Compd., 485, 46 (2009).

[31] Л.К. Марков, А.С. Павлюченко, И.П. Смирнова. ФТП, 53, 181 (2019).

[32] C.H. Chiu, P.C. Yu, C.H. Chang, C.S. Yang, M.H. Hsu, H.C. Kuo, M.A. Tsai. Opt. Express, 17 (23), 21250 (2009).

\section{Application of atomic layer deposition for obtaining nanostructured $I \mathrm{TO} / \mathrm{Al}_{2} \mathrm{O}_{3}$ coatings}

\author{
L.K. Markov ${ }^{1}$, A.S. Pavluchenko ${ }^{1}$, I.P. Smirnova ${ }^{1}$, \\ M.V. Mesh ${ }^{2}$, D.S. Kolokolov ${ }^{2,3}$ \\ ${ }^{1}$ loffe Institute, \\ 194021 St. Petersburg, Russia \\ ${ }^{2}$ Koltsov's Design Bureau, \\ 198097 St. Petersburg, Russia \\ ${ }^{3}$ Institute of Chemistry, St. Petersburg State University, \\ 198504 St. Petersburg, Russia
}

\begin{abstract}
In this work, additional nanometer-thick $\mathrm{Al}_{2} \mathrm{O}_{3}$ layers were grown by atomic layer deposition on nanostructured optically transparent conductive indium-tin oxide coatings obtained by electron-beam evaporation. The indium-tin oxide coatings formed by whiskers of predominantly vertical orientation and characterized by an effective refractive index decreasing monotonically in the direction perpendicular to the substrate were used. The effect of deposited $\mathrm{Al}_{2} \mathrm{O}_{3}$ layer thickness on optical characteristics of the obtained samples is studied. It has been shown that the use of atomic layer deposition method allows one to uniformly cover filamentary crystals of thick nanostructured indium-tin oxide films, in which the upper whiskers obscure the underlying ones, with protective shells; as a result, more resistant to the external environment antireflection conducting coatings with the desired parameters can be obtained. When a protective $\mathrm{Al}_{2} \mathrm{O}_{3}$ layer is deposited, the gradient behavior of the refractive index typical for the initial indium-tin oxide film is kept constant.
\end{abstract}

